\title{
Rivera Farfán, Carolina (CoOrd.) (2014). Trabajo y vida cotidiana de CENTROAmericanos en la frontera suroccidental de MÉxico. MéXICO: CIESAS.
}

\author{
Blanca Mónica Marín-Valadez
}

$T$ Tabajo y vida cotidiana de centroamericanos en la frontera suroccidental de México es un libro coordinado por Carolina Rivera Farfán, compuesto por siete capítulos en los que se reflexiona sobre el fenómeno migratorio centroamericano, principalmente en la zona del Soconusco del estado de Chiapas. Los primeros cuatro capítulos se centran principalmente en la población guatemalteca, y los otros tres en poblaciones centroamericanas de Honduras y El Salvador que trabajan en la región.

Si bien la migración centroamericana es de vieja data, como lo dice Carolina Rivera en la introducción del libro, en los últimos años se ha intensificado. Por un lado, se encuentran aquellos migrantes centroamericanos que, en la búsqueda del sueño americano, cruzan por el territorio mexicano enfrentándose a diversas condiciones de inseguridad que despliegan el crimen organizado y algunas instituciones gubernamentales, que en vez de salvaguardar la integridad de las personas respetando los derechos humanos, actúan como otro tipo de delincuencia. Por otro lado, se encuentran las mujeres y hombres migrantes centroamericanos que por diferentes circunstancias han tomado la decisión de vivir y trabajar en México. El libro se enfoca principalmente en estos migrantes que trabajan en la zona del Soconusco y que, por diversas circunstancias, han tomado la decisión de residir en la región.

Blanca Mónica Marín Valadez. Estudiante de doctorado en Estudios Mesoamericanos en el Instituto de Investigaciones Filológicas de la Universidad Nacional Autónoma de México. Correo electrónico: quetzalazul@gmail.com.
Uno de las aportes más importantes del libro es su carácter multidisciplinario, pues desde la sociodemografía, la sociología y la antropología los autores se plantean dos preguntas básicas: ien qué se ocupan laboralmente los migrantes centroamericanos en los municipios que conforman la zona del Soconusco? ¿cómo transcurre su vida cotidiana en relación con su actividad laboral?

En la parte introductoria Carolina Rivera Farfán nos dibuja el escenario social de la franja fronteriza de Tecún Umán (Guatemala) y Ciudad Hidalgo (México). A través de un conmovedor retrato, la autora dibuja los rostros de personas que cruzan esta frontera y narra los afanes en que se involucran los migrantes durante la espera para cruzar los controles migratorios y obtener un permiso para trabajar en los estados del sureste mexicano. También retrata el cruce de migrantes a través del río Suchiate y los neumáticos que fungen como balsas, que van de un lado a otro llevando personas y mercancías de todo tipo; identifica el dinamismo de aquellos que, viviendo en Guatemala, cruzan con agilidad la frontera de manera habitual, y de los que, desconociendo los códigos de la dinámica, pasan temerosamente frente a los agentes migratorios. Éstos posiblemente serán los que busquen llegar a Estados Unidos. La falta de control en el espacio despierta suspicacias: ipor qué los agentes fronterizos les permiten el paso?

Recibida: 9 de febrero de 2016. 
Otra de las reflexiones que se plasman en la parte introductoria del libro versa sobre las iniciativas de la Comisión Económica para América Latina y el Caribe (CEPAL) y del Sistema de Integración Centroamericano (SICA) para abrir las fronteras entre Guatemala, Honduras, El Salvador y Costa Rica, lo que permitió la creación de relaciones interregionales entre estos países. Además, para favorecer esta movilidad se creó el Parlamento Centroamericano (PARLACEN) en el marco de una red que integra tres dimensiones del proceso regional: económica, política y social (p. 17). La autora señala, citando las reflexiones de Abelardo Morales, que México no pertenece, en estricto sentido, a esta red de países centroamericanos, aunque cada vez su vínculo con Guatemala, en diversos temas que incumben a ambas naciones, precisa de permanentes encuentros debido a la intensa dinámica interregional en la frontera suroccidental de México con Centroamérica.

El contexto social que nos describe Carolina Rivera Farfán en la parte introductoria es el preámbulo para la exposición de los trabajos que abonan al conocimiento sobre esta región en particular.

El primer capítulo es de Jéssica N. Nájera Aguirre y lleva como título "Dinámica actual de la movilidad transfronteriza de los trabajadores guatemaltecos a Chiapas". El texto nos describe cómo transcurre la vida cotidiana de quienes, viviendo en el departamento de San Marcos, en Guatemala, cruzan la frontera de manera habitual para trabajar en diferentes actividades, principalmente en la zona de fincas cafetaleras y bananeras del Soconusco, a través de ciertas prácticas migratorias que se insertan en un contexto transfronterizo. La autora señala que el intercambio comercial y poblacional en esta región fronteriza es histórico, por lo que parte del trabajo se concentra en mostrar a México como un país receptor de inmigrantes trabajadores temporales y a Guatemala como un país expulsor de éstos.

El trabajo de Nájera se inscribe dentro de los estudios sociodemográficos. Su estrategia metodológica parte de una serie de entrevistas desde el enfoque cualitativo, así como de la Encuesta Sobre Migración en la Frontera Sur de México (EMIF Sur 2011) desde el enfoque cuantitativo. Su análisis tiene la intención de mostrar un panorama general de los pormenores laborales articulados a la migración transfronteriza en la zona del Soconusco:

En general el trabajo analítico con base en la Emif Sur permite señalar que el flujo laboral de guatemaltecos a Chiapas no es homogéneo, sino que presenta diversos matices, relacionados con el sexo del migrante, la forma asalariada, el oficio que desempeña, la ubicación de su lugar de trabajo en Chiapas, la forma asalariada por cuenta propia en que participa en el mercado laboral mexicano y la modalidad temporal que adopta para movilizarse a México (p. 5l).

Desde el punto de vista cualitativo, el trabajo de Jéssica Nájera rescata las expresiones de los propios agentes que, a través de sus experiencias, nos muestran el acontecer de su vida cotidiana entre México y Guatemala; entre los ires y venires que implica vivir de un lado de la frontera y trabajar del otro.

Carolina Rivera es la autora del capítulo 2 titulado "Niños, niñas y adolescentes centroamericanos en el mercadolaboral de la frontera Guatemala-México. Hacia la evidencia de una presencia encubierta y simulada". La autora señala oportunamente que la literatura sobre niños, niñas y adolescentes que trabajan ha generado ciertas discusiones que no han promovido consensos para mejorar las condiciones laborales de estos actores, ya que su trabajo se sigue pensando como una actividad de ayuda o como parte de la economía familiar.

En su trabajo, la autora muestra cómo los niños y adolescentes son protagonistas activos en el trabajo agrícola, específicamente en las actividades que corresponden al cultivo del café y al corte de caña, porque, a pesar de las prohibiciones por parte de la Secretaría del Trabajo del Gobierno del Estado de Chiapas, estas prácticas persisten.

Rivera señala cómo el análisis de la migración durante algunos años se había enfocado casi exclusivamente a observar las dinámicas migratorias de hombres y mujeres en edad adulta, pero pocos trabajos versan sobre la movilidad transfronteriza de niños, niñas y 
adolescentes. La investigación presentada por esta autora, significa, por ello, un gran aporte a los estudios sobre migración. Su análisis nos lleva a preguntarnos, en el contexto actual de migración internacional: iquiénes son esos niños y adolescentes que trabajan vendiendo chicles, dulces, cigarros o en las fincas agrícolas?, ¿están acompañados?, ¿dónde se refugian?, ¿son cooptados por enganchadores, por traficantes? Pero, sobre todo, ¿cómo despliegan su capacidad de acción dentro de una esfera social que ha intentado hacerlos invisibles?

El trabajo de Carolina Rivera, desde el análisis cuantitativo y cualitativo, sin lugar a dudas es una aproximación al trabajo invisibilizado que realizan niñas y niños procedentes de Guatemala en la zona del Soconusco y muestra una gran sensibilidad al narrar su aportación a una economía precaria.

"Migración femenina, 'trabajo muerto' y nichos sociolaborales" es el trabajo que comparte Blanca Blanco Abellán y que integra el capítulo 3 del libro. Desde los estudios de género, la autora hace una completa descripción de las motivaciones para migrar de mujeres guatemaltecas que trabajan en el servicio doméstico en Tapachula. Muestra la transición entre vivir en una zona rural de Guatemala, bajo el ojo familiar y comunitario que observa, controla y castiga el comportamiento de estas mujeres, y vivir en una ciudad cosmopolita como Tapachula, donde, según ellas, pueden alcanzar la libertad. Matiza qué les conduce a migrar, ya que no sólo lo hacen para obtener un ingreso económico; Blanco las describe como mujeres con alas, que tienen la curiosidad de conocer otros mundos, otros espacios.

La autora da voz a Abigail, una de sus colaboradoras, que nos sitúa en su propia historia y nos lleva a comprender los vaivenes de sus circunstancias. Una de las aportaciones de Blanca Blanco es mostrar las discusiones sobre las distintas modalidades entre los conceptos "trabajo doméstico", "empleada doméstica" y "empleada del hogar", a la vez que destaca las prácticas y asociaciones que implican estas actividades en los imaginarios sociales, pero sobre todo argumenta cómo la relación entre empleadora y empleada se manifiesta a través de fronteras simbólicas, tal vez producto de la propia región.
En esalógica, el capítulo 4, "Tirandocaña, experiencias laborales-migratorias de adolescentes guatemaltecos cortadores de caña”, escrito por Jania E. Wilson González, nos empuja a conocer las experiencias de adolescentes guatemaltecos que migran durante la época de la zafra para trabajar como cortadores de caña en el ingenio azucarero ubicado en Huixtla, uno de los municipios que forman parte del Soconusco chiapaneco.

Jania Wilson realiza una profunda reflexión sobre cómo ciertas categorías analíticas reducen el comportamiento social a las categorías de explotador y explotado. De acuerdo con el diálogo que establece con distintos autores, como De Carteau y Sheper-Huges, reconoce que los individuos no somos seres pasivos, sino capaces de movernos dentro de las estructuras. Esta postura no niega las condiciones de marginación y pobreza que nos pueden colocar en circunstancias desfavorables. Sin embargo, la autora en su trabajo no sólo muestra estas estructuras dominantes y de riesgo cuando describe el contexto social y laboral de Huixtla y del ingenio azucarero, sino que además revela cómo se puede entretejer en la vida cotidiana de estos agentes.

El trabajo de Jania Wilson se articula con los anteriores, pues coincide con las revisiones históricas de Rivera y Blanco en los capítulos anteriores al mencionar la vieja relación interregional entre Guatemala y México, específicamente entre el departamento de San Marcos, en Guatemala, y la zona del Soconusco en México, relación que, entre otros factores, ha generado una intensa movilidad de guatemaltecos que, ahora adultos, comenzaron a participar en esta actividad laboral desde su infancia.

Jaime Rivas Castillo realiza una gran aportación con su magnífico artículo titulado "Trayectorias emergentes, historias recurrentes, inmigrantes salvadoreños en el Soconusco de Chiapas". Abre la reflexión con una pregunta que desarrolla toda una discusión: ipor qué la gente sigue emigrando desde Centroamérica? Aunque la pregunta posiblemente tiene múltiples respuestas, el autor señala en concreto que la inmigración de salvadoreños al Soconusco, específicamente a Puerto Madero, tiene diversas aristas; acuden para buscar no sólo un nuevo lugar donde vivir, sino un refugio 
para escapar de las condiciones de violencia que padece este país. Es decir, las motivaciones de los inmigrantes salvadoreños van más allá de mejorar su poder adquisitivo.

Rivas analiza la marginalidad, la pobreza y las condiciones desiguales que subsisten en el istmo centroamericano, específicamente en Guatemala, Honduras, Nicaragua y El Salvador, donde el imaginario del centroamericano en proceso de migración está relacionado con la ilegalidad y con el constante desafío de cruzar fronteras, subirse a los trenes mexicanos e internarse en la incertidumbre de una selva que presenta desafíos, promesas y nuevos horizontes. Sin embargo, no todos pueden acceder a ello, por lo tanto, Puerto Madero representa no sólo un espacio para refugiarse, para vivir, sino que además es una grieta que aparece en la última frontera del sur, un puente donde pueden trasladar sus vidas, donde pueden encontrar seguridad a pesar de la marginalidad.

Jaime Rivas da la voz a salvadoreños que se presentan a sí mismos: Blanca, Pedro, Rolando, Eduardo y Ricardo. Son cinco testimonios que nos ayudan a comprender las motivaciones que los han llevado a vivir a Puerto Madero. En un ejercicio dialógico, el autor nos orienta hacía nuevas problemáticas sociales y teóricas para los estudios migratorios, pues estos personajes han tenido que salir de su país, un país fragmentado por la violencia de las pandillas y la corrupción de las autoridades, y donde las expectativas de conquistar el sueño americano se ven truncadas en Puerto Madero. Pero, ¿qué significa este lugar en la vida de cada uno de los inmigrantes salvadoreños? Estas respuestas las encontramos en la descripción y análisis del texto, que aporta nuevas preguntas para los estudiosos de la migración internacional.

El siguiente capítulo lleva por título "Vivir y trabajar en la ciudad de Tapachula, Chiapas. El caso de inmigrantes de origen hondureño". Su autora, Carmen Fernández Casanueva, comienza el trabajo contextualizando al lector sobre las diversas oleadas migratorias de hondureños hacia Estados Unidos, así como sobre la migración interna tras la crisis bananera en las décadas de 1980 y 1990 en Honduras.
Fernández ofrece un sintético recorrido de la historia reciente del país donde destaca, por su importancia, el huracán Mitch, que impactó negativamente en el país centroamericano y generó condiciones de precariedad que no se superaron. El efecto sobre la economía profundizó desigualdades sociales insostenibles, como la falta de vivienda y trabajo o la inseguridad, lo que indudablemente intensificó la emigración de vastos sectores de la sociedad hondureña.

Señala que Tapachula, antes del impacto del huracán Stan - otro fenómeno que afectó la economía y la infraestructura del Soconusco y de grandes regiones de Centroamérica - era un lugar de paso para migrantes hondureños hacia Estados Unidos. Después de la catástrofe, la percepción cambió y pasó a convertirse en un lugar de destino para miles de centroamericanos, ya que la inseguridad que generan las rutas migratorias mexicanas hacía el país del norte ha promovido que éstos se asienten en Tapachula, un lugar donde pueden encontrar trabajo y establecerse con o sin documentos migratorios que acompañen su legal estancia.

Este capítulo nos lleva a conocer las circunstancias, los imaginarios sociales y las diversas fronteras geopolíticas, simbólicas, internas y sociales que tienen que enfrentar en su cotidianidad estos inmigrantes quienes, con el transcurso del tiempo, se integran a la sociedad tapachulteca. El estudio nos muestra las diversas actividades laborales que desempeñan los inmigrantes hondureños, así como las estrategias y las nuevas formas de vida que van desarrollando. Tapachula no era el destino ideal, pero era lo que estaba ahí. Aprendieron a sortear la vida en ese lugar y algunos no han perdido la esperanza de retomar el camino.

Elúltimo capítulo que compone este libro pertenece a Jorge Choy Gómez y lleva por título "Espacios de la vida cotidiana. Una reflexión sobre las relaciones intergeneracionales y la esfera escolar de personas migrantes hondureñas y sus descendientes en Tapachula, Chiapas". El autor articula su reflexión con la de Carmen Fernández Casanueva al hacer una revisión histórica de las oleadas migratorias de hondureños, y nos acerca a diferentes grupos familiares que han tenido que ajustar sus vidas a la condición de 
migrantes. Plantea diferentes problemáticas, como la maternidad transnacional, los conflictos, las tensiones y las negociaciones que madres e hijos tienen que sortear cuando la primera decide migrar y dejar a los hijos al cuidado de parientes cercanos. Realiza un completo análisis a partir del caso de una familia en la que sus miembros pertenecen a diferentes países: iqué ocurre cuando los diferentes miembros de una familia, que se conformó en la distancia, se rencuentran en un espacio como Tapachula?, ¿cómo manejan los individuos estas cercanías a las que no estaban acostumbrados? Las respuestas a estas preguntas las podemos encontrar en el registro etnográfico que realiza el autor

Jorge Choy analiza el comportamiento de estos adolescentes y niños que se insertan en los modelos educativos de Tapachula y sus diferentes personalidades, influidas por el mismo proceso trasnacional en el que han crecido y que tiene un impacto significativo en su desarrollo académico.

Para finalizar, considero que los textos presentados por los diferentes autores y autoras que participan en este libro aportan un conocimiento actual y muy significativo a los estudios migratorios. La frontera suroccidental de México sólo hasta muy recientemente ha comenzado a atraer la atención de los estudiosos. En ese sentido, la aportación y esfuerzo que hacen los autores nos permiten reflexionar sobre los alcances teóricos, metodológicos y epistemológicos necesarios para comprender la movilidad en una frontera con características muy particulares.

Es necesario y pertinente comenzar a discutir las viejas categorías de las ciencias sociales que posiblemente nublan nuestra mirada y, sobre todo, las aproximaciones metodológicas que van más allá de una simple observación. Los autores en sus diversos trabajos se acercan, dialogan, discuten y empatizan con sus colaboradores, y hacen posible que el lector se sumerja en los contextos, experiencias y relatos de cada uno de los personajes.

Cada capítulo que integra este libro nos lleva a conocer el Soconusco: Tapachula, el río Suchiate, Puerto Madero y Huixtla y su ingenio azucarero, junto con los agentes que, a pesar de las condiciones sociales, de los estereotipos construidos, se mueven en la región.

\section{Notas}

1 Estos actores son categorizados como commuters, personas que viven de un lado de la frontera y que se desplazan diariamente, o muy a menudo, al otro lado, y cuya permanencia es de horas, como se expone en el capítulo l (p. 13). 